\title{
Gerenciamento estratégico da informação por meio da utilização da inteligência competitiva e da gestão do conhecimento - um estudo aplicado à indústria moveleira do RS
}

\author{
Strategic Management of Information through the use of competitive \\ intelligence and knowledge management - a study applied to the \\ furniture industry in Rio Grande do Sul, Brazil
}

\author{
Carlos Eduardo Roehe Reginato' \\ Odacir Deonísio Gracioli²
}

\begin{abstract}
Resumo: Com a concorrência no cenário mundial cada vez mais acirrada, para que as empresas se tornem competitivas, existe a necessidade de conhecer e entender as mudanças que ocorrem em um ambiente globalizado. Ambiente este, que não se restringe apenas ao ambiente externo, mas também ao ambiente interno à organização. As empresas devem definir claramente, quais são suas estratégias quanto à informação, para que possam buscar, assim, melhor posicionamento de mercado. Este trabalho apresenta os resultados de um estudo exploratório, sobre a gestão estratégica da informação aplicada à indústria moveleira da região de Bento Gonçalves do Estado do Rio Grande do Sul. Os resultados alcançados identificam as características das empresas quanto à coleta, difusão e sistematização da informação e apresentam como estão sendo utilizadas a gestão do conhecimento e a inteligência competitiva.

Palavras-chave: Planejamento estratégico. Gestão da informação. Informação estratégica. Inteligência estratégica. Gestão do conhecimento.
\end{abstract}

\begin{abstract}
In other to become competitive in the current context of fierce global competition, companies need to recognize and understand the changes that occur in a globalized environment, which involves both the external and the organization's internal environment. Companies should clearly define their information strategies in order to achieve better market position. This paper presents the results of an exploratory research on strategic information management applied to the furniture industry in the region of Bento Gonçalves, Rio Grande do Sul State. The results obtained show characteristics of companies in terms of information collection, dissemination, and systematization and indicate how knowledge management and competitive intelligence are being used by them.
\end{abstract}

Keywords: Strategic planning. Information management. Strategic information. Strategic intelligence. Knowledge management.

\section{Introdução}

Vivemos hoje em uma economia sem fronteiras que impõe cenários versáteis, exigindo que as organizações conheçam bem o ambiente no qual estão inseridas para fazer frente às ameaças e oportunidades que surgem.

Atualmente, para que as empresas tornem-se competitivas, há a necessidade de conhecimento e de entendimento das mudanças que ocorrem em um ambiente globalizado. Os mercados até então

denominados "tradicionais" sofrem rápidas alterações, tornando-se altamente competitivos. A competição surge, não apenas de concorrentes tradicionais e de seus mercados, ou a partir de novos entrantes em determinados setores industriais, mas a partir da desintegração de barreiras de acesso a mercados anteriormente isolados e protegidos (TAPSCOTT; CASTON, 1995).

\footnotetext{
${ }^{1}$ Núcleo de Gestão de Mercados e Sustentabilidade, Centro de Ciências Sociais e da Educação - CCSE, Universidade de Caxias do Sul - UCS, Campus Universitário da Região dos Vinhedos - CARVI, Rua Alameda João Dall Sasso, 800, Bairro Universitário, CEP 95700-000, Bento Gonçalves, RS, Brasil, e-mail: cerregin@ ucs.br

${ }^{2}$ Núcleo de Gestão de Mercados e Sustentabilidade, Centro de Ciências Exatas, da Natureza e da Terra - CENT,

Universidade de Caxias do Sul - UCS, Campus Universitário da Região dos Vinhedos - CARVI, Rua Alameda João Dall Sasso, 800, Bairro Universitário, CEP 95700-000, Bento Gonçalves, RS, Brasil, e-mail: odgracio@ ucs.br
}

Recebido em 25/8/2010 — Aceito em 27/6/2012

Suporte financeiro: Universidade de Caxias do Sul - UCS. 
Sendo assim, as empresas não podem mais esperar que os produtos e práticas que fizeram seu sucesso no passado possam mantê-las viáveis no futuro. Pressões de preço não deixam espaço para a produção ineficiente. $\mathrm{O}$ ciclo de desenvolvimento de produtos e sua introdução no mercado duram cada vez menos tempo. Impedir que os concorrentes copiassem ou ainda aperfeiçoem novos produtos e métodos de produção numa economia caracterizada pelo livre fluxo de ideias, marcada pela utilização de técnicas como a engenharia reversa, benchmarking e a inteligência competitiva, tornam-se cada vez mais difícil.

De acordo com a Associação das Indústrias de Móveis do Estado do Rio Grande do Sul - MOVERGS (2009), a indústria de móveis de Bento Gonçalves encontra-se muito bem organizada em um arranjo produtivo local, onde está localizado o maior polo moveleiro do Brasil. Este polo caracteriza-se por apresentar uma elevada fragmentação, formada, na sua maioria, por empresas de pequeno porte, de caráter familiar, tradicional e de capital inteiramente nacional. Opera com tecnologia de ponta que lhe permite competir por meio de uma estratégia de custos. Graças à união do arranjo e de uma governança central forte, foi possível minimizar um dos problemas que a indústria enfrentava quanto à localização geográfica. Dispõe hoje de fornecedores mais próximos da indústria, diminuindo assim os custos com o transporte e aumentando a oferta de matéria-prima. Outro ponto importante a destacar, que já está sendo construído desde 1996, é a busca por um design próprio que permita à indústria moveleira competir em diferenciação.

Porém, a indústria de móveis de Bento Gonçalves, ainda apresenta algumas deficiências quanto às estratégias de comercialização. Por meio do planejamento formal, podem-se traçar estratégias para a busca de melhor posicionamento. Conhecer as necessidades de informação é fator imprescindível para um bom planejamento.

Sendo assim, a utilização da inteligência competitiva, proporciona o monitoramento do ambiente externo, das oportunidades e ameaças, na identificação de sinais fracos de mercado, que permitam uma postura mais antecipativa. Por sua vez, com a utilização da gestão do conhecimento, por meio da construção de uma memória organizacional, será possível armazenar informações informais provenientes do ambiente interno.

Com a utilização da gestão estratégica da informação será possível, traçar estratégias condizentes com as atividades de negócio da empresa e, consequentemente, gerar maior valor agregado aos produtos ofertados.

O presente estudo, portanto, coloca em evidência a importância da gestão da informação. Portanto, o objetivo geral deste trabalho é a gestão estratégica da informação, em que será apresentado como a indústria moveleira do arranjo produtivo de Bento Gonçalves do Estado do Rio Grande do Sul utiliza seus recursos informacionais e como estas utilizam a gestão do conhecimento e a inteligência competitiva. Por fim, o presente estudo apresenta algumas sugestões para as empresas da indústria moveleira na elaboração das estratégias de informação.

\section{Gestão da informação}

A cada dia que passa, a informação vem desempenhando um papel vital para as organizações. Gerencia-lá de modo eficaz, usando-a como um recurso estratégico, contribui de maneira fundamental para um bom planejamento. Competir no cenário atual requer organizações que sejam proativas em suas ações de mercado, para que se possa assim auferir uma rentabilidade mais elevada.

De posse de informações antecipativas, pode-se orientar os recursos disponíveis, suas competências e habilidades, para fazer frente a exigências de mercado. Reagir de forma rápida e precisa são condições fundamentais para as empresas que desejam ser mais competitivas.

Para Lesca (1996), as empresas devem desenvolver mecanismos de pesquisa e de busca por dados e informações, consideradas críticas que ofereçam subsídio não apenas às atividades operacionais, mas sim auxiliem no processo de planejamento e na busca de melhor posicionamento. Para Fuld (2008), quem se destaca no mercado, ou seja, tem uma lucratividade mais elevada, são as organizações que executam as melhores estratégias.

Grande parte das informações necessárias ao processo de tomada de decisão já se encontram dentro da empresa. Alguns autores afirmam que mais de $80 \%$ delas residem nos sistemas de informação como conhecimento explícito, outras residem nos colaboradores na forma de conhecimento tácito (LAUDON; LAUDON, 2002; STAIR; REYNOLDS, 2002; TURBAN; McLEAN; WETHERBE, 2004). Para tanto, é necessário que os sistemas de informação sejam capazes de recuperar a informação em tempo hábil, fornecendo assim condições de aumentar a capacidade de resposta da empresa.

De acordo com o exposto, isto é possível pelo monitoramento do ambiente, no qual podem ser identificados sinais fracos, que geralmente podem ser traduzidos em informações potenciais. Estes sinais são pouco evidentes e necessitam ser detectados e amplificados, o que requer que a empresa esteja organizada para a coleta, análise e sistematização da informação.

Estes sinais podem ser encontrados tanto no ambiente externo como no ambiente interno. Desta forma, os tomadores de decisão precisam compreender melhor os pontos fortes e fracos (ambiente interno) da organização para fazerem 
frente às oportunidades e ameaças (ambiente externo), (ANSOFF; McDONNELL, 1993; LESCA, 1996; MILLER, 2002; DAVENPORT; HARRIS, 2007).

Por conseguinte, a Inteligência Competitiva - IC e a Gestão do Conhecimento vêm suprir esta necessidade. Não apenas por novas informações, mas sim por meio de uma base de conhecimento ou de uma memória organizacional, em que se encontram valores, informação contextual e insight experimentados, o que proporciona à organização uma estrutura para a avaliação e incorporação de novas experiências e informações ao processo decisório da empresa (CORNELLA, 1994; ALTER, 1996; NONAKA; TAKEUCHI, 1997; DAVENPORT; PRUSAK, 1998; BUKOWITZ; WILLIAMS, 2002; MILLER, 2002).

Para que o compartilhamento do conhecimento tácito ocorra de forma satisfatória é necessário que a empresa tenha um bom fluxo de informações que estimule o processo de comunicação.

\subsection{Comunicação nas organizações}

A comunicação organizacional pode ser definida como todo o processo realizado por uma organização com o intuito de informar seu público interno ou externo. No que se refere ao público interno, a comunicação pode ser feita por correio eletrônico institucional, reuniões, palestras, atividades de treinamento, jornal de circulação interna, mural, entre outros veículos de comunicação que poderiam ser citados (SCHERMERHORN; HUNT; OSBORN, 1999). As conversas e encontros informais dos funcionários dentro da empresa também fazem parte deste processo.

Por sua vez, comunicação, para Chiavenato (2009a), Bowditch e Buono (1999) e Kotler e Keller (2006), é a transmissão de uma informação de uma pessoa a outra ou de uma organização a outra. A comunicação é o fenômeno pelo qual um emissor influencia e esclarece um receptor, ou ainda, comunicação é o processo pelo qual a informação é intercambiada, compreendida e compartilhada por duas ou mais pessoas, ou entre organizações, com a intenção de influenciar um determinado comportamento.

Neste contexto, insere-se o tomador de decisão onde os apectos inerentes ao ambiente criam situações que, na maioria dos casos, estão fora do seu controle, conhecimento e compreensão, interferindo assim no processo de tomada de decisão. Assim sendo, o risco de insucesso está associado diretamente à capacidade da empresa em prover a informação. A chave para a comunicação organizacional encontra-se na disposição e na estrutura de como a comunicação é dirigida às pessoas específicas e grupos que dela precisam para fins de trabalho, soluções de problemas, controle ou tomada de decisão.
Além das limitações anteriormente mencionadas, existem as barreiras à comunicação que podem ser instauradas ao longo deste processo. Estas restrições compõem uma série de fatores organizacionais, interpessoais e individuais que podem dificultar a comunicação entre grupos e organizações.

Portanto, a falta de definição de um glossário de termos, interferências exercidas por pessoas ou por um determinado grupo movido por ideias, emoções ou por interesses podem prejudicar o processo de comunicação. A própria centralização é um dos problemas que surgem com o tempo e que interferem neste processo. À medida que a empresa cresce e se solidifica no mercado deve haver a preocupação com a descentralização, o que lhe proporcionará ao longo do tempo condições de construir um fluxo de informação adequado. Além disto, questões físicas de infraestrutura também prejudicam. Falta de recursos para investimentos em sistemas de informação ou falta de infraestrutura disponível no local em que a unidade de negócio está instalada geram barreiras à comunicação (LAUDON; LAUDON, 2002; STAIR; REYNOLDS, 2002; TURBAN; McLEAN; WETHERBE, 2004).

Assim sendo, a comunicação organizacional é o processo segundo o qual a informação é sistematizada e difundida por meio da organização e de seu ambiente (BOWDITCH; BUONO, 1999). O fluxo de informações deve dar suporte adequado à elaboração e revisão do planejamento estratégico, bem como ao processo de tomada de decisão.

\subsubsection{Sistematização e difusão da informação}

Para que a empresa seja competitiva, não basta somente coletar informações externas, é preciso que conheça suas possibilidades e limitações quanto à obtenção, sistematização e difusão das informações.

A empresa é um sistema aberto e, portanto, deve interagir com o ambiente e adequar-se a ele. Como um subsistema dentro de um sistema maior, ela está permanentemente influenciando e sendo influenciada pelo ambiente. A não compreensão exata desse fato levou uma geração de administradores a se concentrar nos problemas de eficiência interna do sistema e não nos problemas estratégicos que resultam da interação de fenômenos do meio ambiente que afetam a empresa (ALTER, 1996; NONAKA; TAKEUCHI, 1997; DAVENPORT; PRUSAK, 1998; MILLER, 2002; DAVENPORT; HARRIS, 2007). Sendo assim, a empresa existe para produzir resultados (eficácia) e estes são obtidos quando a empresa consegue atender às necessidades do ambiente externo. O que também envolve a habilidade da empresa em suplantar as naturais pressões sobre ela exercidas pelo ambiente. 
Em contrapartida, na maioria das organizações, a informação interna é considerada muito mais importante do que a informação externa (CORNELLA, 1994; NONAKA; TAKEUCHI, 1997; DAVENPORT; PRUSAK, 1998; MILLER, 2002; DAVENPORT; HARRIS, 2007). Isso ocorre, em geral, segundo os autores, porque o volume de informações internas é geralmente maior, e a organização, no seu dia a dia, produz grande quantidade de informações. Em segundo lugar, a informação interna é fundamental a uma organização no processo de intercâmbio e interação entre as pessoas que dela fazem parte. Assim, tanto a informação interna como a externa são importantes para a organização.

A difusão das informações, segundo Lesca, Freitas e Cunha Junior (1996), ocorre quando estas estiverem disponíveis àqueles que podem transformá-las em ação, seja na formulação de estratégias ou na resolução de problemas. Seja qual for a informação existente na organização, seja interna ou externa ou ainda formal ou informal, deve-se permitir que haja acesso rápido a estas informações. A integração proporciona a racionalização dos processos de gerenciamento de informação. Por meio dela, pode-se otimizar a utilização dos recursos envolvidos, fazendo com que todos tenham acesso e venham a ser os alavancadores na obtenção e difusão das informações na organização. Deveria se tornar a nova filosofia das empresas, vista com bons olhos pelos seus dirigentes.

\subsection{Inteligência Competitiva}

A área de Inteligência Competitiva - IC, por meio do uso de informações concorrenciais, contribui de forma significativa para a redução das incertezas e o aumento na qualidade do processo decisório empresarial. Por meio das operações de busca de inteligência, uma empresa pode detectar mudanças que tenham acontecido em seu ambiente de negócios, colocando-se em uma posição para tomar decisões mais efetivas do que as que têm sido tomadas sem a informação (ALTER, 1996; DAVENPORT; PRUSAK, 1998; MILLER, 2002; PRESCOTT; MILLER, 2002; DAVENPORT; HARRIS, 2007; FULD, 2008).

A IC pode ser definida como o processo de busca da informação e do conhecimento a ser obtido e usado para a formulação estratégica. A alta administração deve conduzir o esforço de IC, mas todos os empregados devem ser envolvidos e realmente capacitados para contribuir com este esforço (LUECAL; DAHL, 1995; FULD, 2008). Da mesma forma, Festervand e Murrey Junior (1993) definem IC como a informação sobre ações, capacidades e intenções do atual ou potencial concorrente, que supre a entrada de informações para a formulação de estratégias e objetivos a longo prazo. A busca de IC envolve, além do uso de estatísticas de uso da indústria, a utilização de investigações sobre o concorrente para obter informações específicas disponíveis sobre a pessoa certa, no tempo certo.

Por fim, Vargas (1996) conclui dizendo que IC é um processo que busca instruir-se por meio de informações totalmente públicas e legais, respeitando um rigoroso código ético, porém acompanhando as pistas do setor e da concorrência, tentando identificar oportunidades e focos de inovação, o que deverá permitir tomar melhores decisões, fornecendo informações pertinentes, úteis e críticas para o funcionamento da empresa.

Em suma, a IC constitui-se num processo sistêmico de captação de informações dispersas para melhor entendimento das forças do ambiente externo e interno, que auxiliam na tomada de decisão da empresa.

A transformação dos sinais de alerta em força motriz, primeira etapa do processo de inteligência, consiste na transformação de sinais fracos e dispersos, encontrados no ambiente externo; sinalizando tendências, isto é, oportunidades e ameaças do mercado. Essa transformação objetiva a avaliação e a reformulação de objetivos, bem como consiste na alavancagem de recursos necessários para sua implementação na empresa. As informações qualificadas como força motriz devem ser difundidas por toda a organização para que haja o máximo de envolvimento de todos os participantes.

O próximo passo, o qual é a própria ação que desencadeia os objetivos, necessita, por sua vez, da alavancagem de recursos e habilidades, externos e internos à empresa. Depois dessa série de etapas, a realização de feedback completa o ciclo, isto é, por meio da monitoração do ambiente externo, buscam-se novamente sinais fracos que se transformam em sinais de alerta. Esta última etapa serve como avaliação dos objetivos e dos esforços empreendidos pela empresa, que irão gerar nova força motriz. Assim, pode-se dizer que o processo de inteligência é cíclico, funcionando em movimentos circulares, em que cada etapa acumula novas informações e conhecimentos do estágio anterior.

Por meio do processo de inteligência, a empresa poderá conhecer e entender melhor o seu ambiente. Desta forma, poderá perceber quais as ações dos concorrentes, seus pontos fortes e fracos, sucessos e fracassos, as necessidades dos clientes, as capacidades dos fornecedores, novas tecnologias e, enfim, pode controlar melhor a situação do mercado, ganhando em tempo e competitividade perante a concorrência. Além disso, a utilização dos recursos que a área de IC coloca à disposição permite agregar valor à tomada de decisão, possibilitando formas de diferenciação de atividades, de produtos e de serviços, favorecendo assim, a criação de vantagens competitivas sustentáveis (MILLER, 2002; FULD, 2008). 


\subsubsection{Contrainteligência}

Conforme apresentado anteriormente, a inteligência competitiva permite a uma organização melhorar seu ambiente, melhorando o processo de tomada de decisão, permitindo que ela possa manter uma postura proativa, que lhe proporcione um aumento na capacidade de competição.

Contudo, se o objetivo é buscar melhor posicionamento de mercado, na mesma proporção, deve-se tomar o cuidado de proteger os ativos da empresa, sejam estes tangíveis ou intangíveis. Os pontos levantados neste artigo, quanto à contrainteligência, referem-se à proteção de informações sejam estas provenientes de um processo de desenvolvimento de novos produtos, de campanhas de promoção e propaganda, de estratégias de posicionamento de mercado ou sejam das ações a serem implementadas e difundidas no mercado decorrente do planejamento estratégico da empresa.

O processo de contrainteligência, segundo Nolan e Quinn (apud MILLER, 2002), obedece a um processo ordenado e organizado da mesma forma que o processo de inteligência competitiva. Segundo os autores, a abordagem de contrainteligência é apresentada no "Modelo de Proteção da Inteligência de Negócios" que consiste de sete etapas. A primeira, denominada de definição das propriedades, define uma lista de prioridades e indicadores capazes de despertar a atenção dos concorrentes. Aqui se quer levantar pontos que se deve proteger. A segunda etapa consiste em analisar a concorrência, identificando suas competências e habilidades na coleta de informação e prospecção de negócios. Depois desta etapa devem ser avaliadas as vulnerabilidades da empresa a fim de neutralizá-las. A próxima etapa resulta no desenvolvimento de contramedidas que resultam na elaboração de estratégias com o objetivo de resguardar as informações da empresa. Estabelecida estas estratégias, o próximo passo consiste na aplicação das contramedidas. Com a implementação destas estratégias, tem-se a etapa de análise, em que será necessário o acompanhamento delas para verificar se estas estão gerando o resultado esperado. Por fim, a última etapa, a disseminação, retorna à etapa inicial de definição das propriedades.

Conforme foi apresentado, o modelo de proteção de inteligência de negócios é cíclico e contínuo, operando em conjunto com o modelo de inteligência competitiva.

\subsection{Conhecimento}

Ao definir conhecimento, não se quer com isto esgotar o assunto por meio de uma definição final, mas sim oferecer uma definição funcional de conhecimento dentro de um ponto de vista pragmático que ajude a entender o que vem a ser o "conhecimento nas organizações".

Segundo Davenport e Prusak (1998) e Miller (2002), o conhecimento é uma mistura fluida de experiências condensadas, valores, informação contextual e insight experimentados, a qual proporciona uma estrutura para avaliação e incorporação de novas experiências e informações. Segundo Alter (1996), conhecimento é a combinação de instintos, ideais, normas e procedimentos que guiam a ação e a decisão.

A origem deste conhecimento e sua aplicação se dão na mente dos indivíduos. Dentro das organizações, ele geralmente se encontra não apenas em documentos e/ou repositórios, mas também nas rotinas, processos, práticas e normas organizacionais.

Assim, as empresas geram conhecimentos como resultado de uma assimilação da informação interna e externa e da exploração das capacidades criativas de seus membros. Nas organizações se aprende, e os conhecimentos que são adquiridos vão sendo acumulados em forma de Know-How (CORNELLA, 1994; DAVENPORT, 2006; NONAKA; TAKEUCHI, 2008).

Com a informação e o conhecimento adquirido por meio da experiência dos participantes da organização poderão ser combinados os conhecimentos com a própria capacidade de inovação. Por exemplo, as informações e o aprendizado adquirido com um determinado segmento de clientes poderão fornecer subsídios para o aprimoramento ou desenvolvimento de um novo produto que atenda às necessidades destes clientes. Desta forma, o conhecimento armazenado (Know-How), o aprendizado e a experiência adquirida pelos membros da organização possibilitam agregar valor, podendo se constituir em uma vantagem competitiva.

Analisando o processo de conhecimento, verifica-se que deriva da informação da mesma forma que a informação deriva dos dados. Para que a informação se transforme em conhecimento, segundo Alter (1996) e Davenport e Prusak (1998), é necessário que os recursos humanos da empresa respondam às seguintes perguntas:

- Comparação: de que forma as informações relativas a esta situação se comparam a outras situações conhecidas?

- Consequências: que implicações estas informações trazem para as decisões e tomada de ação?

- Conexões: quais as relações deste novo conhecimento com o conhecimento já acumulado?

- Conversação: o que as outras pessoas pensam destas informações?

A importância do conhecimento para as organizações reside no fato de que ele está muito próximo da ação, mais do que o dado e as informações. 
Desta forma, o conhecimento deve ser avaliado pelo impacto que causa nas decisões. A relação dos níveis de conhecimento organizacionais está correlacionada à capacidade da empresa em armazenar este conhecimento (NONAKA; TAKEUCHI, 1997, 2008; DAVENPORT; PRUSAK, 1998).

Um conhecimento alto, por exemplo, pode proporcionar, à empresa, ganhos de eficiência mensurável em desenvolvimento de produtos e na sua produção. Pode-se usá-lo para tomadas de decisões mais eficazes sobre concorrentes clientes, canais de distribuição, serviços, ou seja, no planejar de forma mais acertada as ações da empresa frente às exigências de mercado.

\section{Metodologia}

Para a realização desta pesquisa, utilizou-se o método exploratório por enquete, com ênfase qualitativa de determinados aspectos da população estudada.

\subsection{Etapas da pesquisa}

A pesquisa envolveu quatro etapas distintas:

1 a etapa: envolveu a coleta de dados sobre a indústria moveleira, por meio de entrevistas com especialistas e análise de conteúdo de períodicos, artigos, dissertações e teses. Nesta fase, foram realizadas entrevistas com profissionais de instituições ligadas à indústria moveleira que permitiram ao pesquisador conhecer melhor as características e a atual problemática do setor de atuação dessas empresas. As entrevistas foram guiadas por um roteiro semiestruturado e algumas questões abertas que foram aplicadas pelos próprios pesquisadores. Os resultados desta etapa permitiram a identificação das variáveis principais e proporcionaram subsídios para a elaboração do questionário definitivo, que foi aplicado posteriormente à amostra das empresas.

\subsubsection{Variáveis envolvidas no estudo}

Com base nas entrevistas que foram realizadas com profissionais do setor moveleiro, na análise de conteúdo e nas contribuições da literatura, o presente estudo levou em consideração as seguintes variáveis:

- Perfil da empresa: agrupou algumas características das empresas tais como: faturamento, número de funcionários, data de fundação, entre outras. Esta variável cruzada com as outras permitirá a descoberta de prováveis relações entre o tipo de empresa e as demais variáveis (ASSOCIAÇÃO..., 2007, 2009);

- Estruturas organizacionais: permitiu verificar quais as estruturas organizacionais utilizadas pelas empresas. Por meio desta variável pôde-se identificar a qualidade do fluxo de comunicação e que tipos de estratégias são pertinentes;

Referencial teórico: fundamenta-se nos conceitos sobre estrutura (NONAKA; TAKEUCHI, 1997, 2008; CORNELLA, 1994).

- Planejamento estratégico: corresponde ao estabelecimento de um conjunto de providências a serem tomadas pelos administradores. Estas providências passam por um processo decisório. Esta variável permitiu identificar quais são as empresas que planejam suas atividades e de que forma o fazem, propiciando assim a análise de como são utilizadas, ou não, as estratégias de comunicação nas empresas a serem estudadas;

Referencial teórico: foi utilizado o modelo de gestão empresarial apresentado no referencial teórico, que mostrou as diversas fontes de informação para o planejamento (PORTER, 1991, 1992).

- Sistemas de informação: esta variável visou identificar quais os sistemas de informação utilizados pelas empresas. A finalidade consistiu em entender como as empresas coletam, difundem e sistematizam suas informações;

Referencial teórico: as teorias utilizadas nesta variável são dos autores (CORNELLA, 1994; ALTER, 1996; STAIR, 1998).

\section{- Inteligência Competitiva, contrainteligência e} gestão do conhecimento: permitiu identificar quais as técnicas que são utilizadas pelas empresas na coleta e difusão das informações;

Referencial teórico: as teorias utilizadas nesta variável são dos autores (NONAKA; TAKEUCHI, 1997, 2008; DAVENPORT; PRUSAK, 1998; PRESCOTT; MILLER, 2002; MILLER, 2002; DAVENPORT; HARRIS, 2007; FULD, 2008).

$2^{\text {a }}$ etapa: nesta etapa, foi realizada a delimitação da população, do tamanho da amostra (de acordo com dados fornecidos pela MOVERGS) e a aplicação do pré-teste do questionário (teste-piloto) para validar o instrumento de pesquisa. A amostra foi delimitada de acordo com os seguintes critérios:

- Pelo cadastramento junto a MOVERGS, incluíram-se somente empresas que estivessem cadastradas nesta base de dados;

- Pelo tamanho, consideraram-se as empresas de pequeno, médio e grande porte; e

- Pela localização geográfica, selecionaram-se as empresas da região do polo moveleiro de Bento Gonçalves/RS.

A amostra totalizou 42 empresas, das quais, 7 destinaram-se ao teste-piloto do questionário, 35 constaram da amostra definitiva da pesquisa. A amostra foi selecionada, por meio de sucessivos 
sorteios, sem reposição, até se obter o número necessário de empresas (amostra aleatória simples).

$3^{\text {a }}$ etapa: consistiu da coleta final de dados, com o objetivo de se obter informações sobre as empresas de como são utilizados seus recursos informacionais por meio do uso da gestão do conhecimento e da inteligência competitiva. O questionário utilizado para a coleta de dados continha questões que procuraram identificar se as empresas conheciam os conceitos sobre o tema (gestão do conhecimento e inteligência competitiva), se afirmativo, quais práticas eram utilizadas, como eram armazenadas e difundidas estas informações e como estas eram aplicadas no processo de gestão estratégica da informação. O questionário foi aplicado pelos próprios pesquisadores em forma de entrevistas com os diretores das empresas definidas na amostra.

$4^{\text {a }}$ etapa: realizou-se a análise e a interpretação dos dados coletados na etapa anterior. Esta fase implicou na tabulação dos dados, na análise e interpretação dos resultados, a fim de atender aos objetivos propostos pelo presente estudo. No tratamento dos dados, utilizou-se a análise qualitativa e quantitativa (com o uso SPHINX..., 2007; SPSS..., 2007).

\section{Resultados da pesquisa}

Com o desenvolvimento da pesquisa, chegou-se aos seguintes resultados, que são apresentados abaixo obedecendo aos objetivos específicos, delineados no projeto de pesquisa.

\subsection{Características gerais da indústria moveleira do polo de Bento Gonçalves - RS}

A indústria moveleira do Estado do Rio Grande do Sul caracteriza-se como uma das principais concentrações de móveis do País. Na região da serra, no munícipio de Bento Gonçalves, encontra-se o maior polo de móveis do Estado, responsável por 29,3\% das exportações nacionais do setor. A indústria do Estado destaca-se por possuir um nível de verticalização da indústria mais baixo em relação aos demais polos do País. As subcontratações chegam a $20 \%$ do volume produzido na indústria.

Por outro lado, destaca-se por sua elevada fragmentação, em que predominam empresas de micro e pequeno porte. $\mathrm{O}$ capital da indústria caracteriza-se por ser estritamente nacional, não existindo até o momento empresas multinacionais. Além disto, a grande maioria das empresas possui uma estrutura centralizada de caráter familiar, pressupondo assim, que as informações e o processo de tomada de decisão estão restritos à alta administração.

Em contrapartida, pode se ressaltar que poucas são as empresas de grande porte. Estas pertencem ao seleto grupo que comanda o mercado, caracterizando-se por possuírem uma administração mais descentralizada e profissionalizada.

Empresas com uma estrutura mais descentralizada, que primam por uma delegação maior da autoridade, ou que buscam uma administração mais profissionalizada e que enfatizam o trabalho colaborativo, conseguem se organizar melhor. Estas empresas possuem um fluxo de informações bem delineado que fomentam um processo de planejamento adequado às condições impostas pelo ambiente externo. Sendo assim, é possível formular estratégias adequadas de acordo com suas necessidades, que permitam melhor posicionamento de mercado, bem como a construção de novas vantagens competitivas.

Porém a grande maioria das empresas não possui um processo de planejamento formal. Devido à elevada centralização de suas estruturas, a tomada de decisão limita-se à alta administração. Desta forma, haver uma comunicação restrita com as demais áreas da empresa, meramente de caráter operacional, prejudica o entendimento das reais necessidades do mercado, implica na aplicação inadequada dos recursos e aumenta o risco de insucesso do negócio.

A grande maioria das empresas toma suas decisões embasadas no conhecimento do dia a dia (feeling), apostando assim no que se pode chamar de improvisação estratégica. Desta forma, a falta de preparo e de conscientização por parte de algumas empresas no monitoramento do ambiente externo, quanto à importância do processo de planejamento e da formulação de estratégias, consiste numa postura muito arriscada. Este tipo de comportamento implica na comunicação e relacionamento inadequado, refletindo-se diretamente na capacidade de competição da empresa.

Quanto à informação, pode-se observar que todas as empresas da amostra possuem sistemas funcionais que permitem a tomada de decisão no nível operacional.

\subsection{Como ocorre o gerenciamento da informação na indústria moveleira}

De acordo com o exposto, após a caracterização da indústria moveleira, a amostra do presente estudo foi subdividida em dois grupos distintos. Esta subdivisão permite identificar o perfil de cada grupo quanto à utilização, sistematização e difusão da informação. Além disto, será apresentado o que cada grupo faz em relação às estratégias de comunicação.

O primeiro agrupamento pode ser assim denominado de "grupo alfa" e o segundo agrupamento de "grupo beta". O grupo alfa é constituído por empresas que possuem sistemas de informação gerencial - SIG, o que representa 34,3\% da amostra, seguido pelas empresas que utilizam os sistemas de suporte a decisão - SAD, que equivale a 8,6\%. Este grupo é formado por empresas de médio e grande 
porte, que representa 28,6\% da amostra. Pode-se constatar que estas empresas possuem estratégias mais bem estruturadas, pois possuem um setor encarregado do gerenciamento da tecnologia e da sistematização da informação.

Pode-se verificar que a estrutura nestas empresas caracteriza-se pela sua decentralização, o que proporciona uma distribuição da informação mais uniforme, chegando a todos os níveis da organização no tempo certo. De posse de informações adequadas, é possível aumentar a capacidade de resposta, permitindo assim a otimização dos recursos disponíveis pela empresa, bem como um possicionamento de mercado mais adequado.

Este grupo utiliza-se do planejamento formal das atividades da empresa e visualiza a informação como recurso estratégico. O estilo ou estado da informação, que predomina aqui, segundo McGee e Prusak (1998), é o estilo denominado de federalismo. Este se caracteriza pelo estímulo à cooperação, ao aprendizado e no consenso e na negocição de elementos-chave, necessários à definição coletiva dos objetivos, marcado pelo compartilhamento da informação.

Analisando o fluxo de informações, pode-se constatar que este ocorre dentro de uma frequência diária e semanal, por meio de relatórios disponibilizados no sistema e de reuniões entre as equipes e entre os diversos níveis hierárquicos.

Porém, cabe ressaltar que 55\% das informações são provenientes de conversas e encontros informais, estando assim armazenadas nos indivíduos que fazem parte da organização. Este conhecimento tácito, fruto da vivência e da experiência adquirida no dia a dia, por parte dos colaboradores, muitas vezes, deixa de ser recuperado e é perdido.

Com a utilização da gestão do conhecimento, é possível armazenar o conhecimento tácito em conhecimento explícito, criando na organização uma memória organizacional, que lhe permita recuperar estas informações.

De acordo com o estudo, apenas duas empresas, o que representa $5,7 \%$ da amostra, afirmam que se utilizam de técnicas de gestão do conhecimento. Estas empresas empregam a técnica de "memória em grupo", na qual os colaboradores são estimulados a socializar suas experiências por meio de relatos verbais e escritos, realizados em reuniões. Espaço este destinado à apresentação de práticas utilizadas e desenvolvidos por um determinado grupo e que pode ser difundido para toda a empresa, caso este seja validado pelos demais. Este conhecimento agora explícito passa a ser armazenado em uma memória organizacional no sistema de informação da empresa. A maioria das inciativas encontradas busca a identificação e sistematização das melhores práticas utilizadas pela empresa em seu ambiente interno. As áreas que se destacam nestas duas empresas foram às áreas de produção e de comercialização. Este número denota um percentual muito baixo se compararmos com o percentual de informações que chegam à empresa de maneira informal. Desta forma, são perdidos ou deixam de ser recuperados dados e informações em tempo hábil, que poderiam agregar valor no processo de tomada de decisão.

Outro ponto a ser destacado é quanto ao uso da Internet. As empresas que compõem este grupo utilizam a rede como um recurso estratégico. Este recurso é empregado para fins comerciais, pelo comércio eletrônico, da divulgação da marca e do marketing institucional. Além disto, é utilizado no monitoramento do ambiente externo, pela análise dos seus concorrentes, clientes, fornecedores, de variáveis como tecnologia, economia, entre outras.

Sendo assim, são empregadas técnicas de inteligência estratégica, com o objetivo de coletar informações públicas e de caráter antecipativo.

Ainda a rede é vista como uma excelente oportunidade de manter um elo com o mercado, por meio do marketing de relacionamento com os clientes.

Por sua vez, o grupo beta, é constituído por empresas de pequeno e médio porte (equivalente a $71,4 \%$ da amostra) que operam com sistemas funcionais, sitemas de processamento de transações - SPTs e sistemas de informação gerencial - SIG. Neste grupo, a grande maioria opera com sistemas de processamento de transações.

Quando é abordada a utilização do planejamento estratégico, pode-se constatar que as empresas conhecem seus objetivos, porém seu processo de elaboração é restrito à alta administração. Devido às características apresentadas anteriormente, as empresas que compõem o grupo beta possuem uma estrutura mais centralizada, na qual as informações de caráter estratégico não são compartilhadas.

De acordo com McGee e Prusak (1998), estas empresas possuem um estilo de gerência da informação denominado de monarquia, oriundo de estruturas mais centralizadas, em que o poder de gerenciamento da informação e a autonomia dos departamentos e unidades são substancialmente reduzidos.

Assim sendo, estas empresas estão focadas em um horizonte de curto e médio prazo, deixando a descoberto questões estratégicas de mercado. Este tipo de postura leva a um comportamento em que se pode observar que algumas empresas estão mais preocupadas em resolver seus problemas operacionais.

Desta forma, o fluxo de informação caracteriza-se por sua irregularidade, o que prejudica a qualidade na tomada de decisões. Os sistemas aqui são subutilizados, vistos apenas como um recurso operacional. Apenas três empresas se utilizam de sistemas de informação gerencial e realizam o processo de planejamento estratégico formal. 
Um exemplo disto é quanto à utilização da Internet, que é vista como uma ferramenta meramente operacional. Neste grupo, técnicas como a gestão do conhecimento e a inteligência competitiva deixam de ser utilizadas pela grande maioria das empresas. Apenas algumas empresas fazem o uso parcial de técnicas de monitoramento competitivo, adotando assim uma postura mais reativa quanto ao mercado. Da mesma forma, acontece com o fluxo de informação que, devido à centralização, torna os fluxos irregulares, que, por sua vez, contribuem para o atraso, redundância e falta de consistência nas informações que chegam para o processo de tomada de decisão. Quando perguntado sobre a utilização da gestão do conhecimento, embora poucas empresas conheçam esta técnica de gestão da informação, nenhuma delas a utiliza.

Contudo, pôde-se observar que a informação deixa de ser tratada como um recurso estratégico, aumentando assim, considerávelmente, o risco de mercado a que estas empresas estão sujeitas.

\subsection{Considerações sobre a utilização de estratégias da informação}

A utilização dos recursos da tecnologia da informação, bem como da utilização adequada das técnicas de gestão da informação, permitem um processo decisório mais ágil e dinâmico. As considerações que aqui serão feitas discorrem sobre as sugestões de melhoria que a indústria poderá adotar no gerenciamento estratégico da informação.

De acordo com o exposto anteriormente, apenas $28,6 \%$ da amostra gerencia a informação de maneira satisfatória. O grupo alfa, assim denominado, procura monitorar o ambiente externo, mostrando uma postura mais antecipativa. Assim sendo, consegue construir cenários de longo prazo que permitam a diluição dos riscos e, consequentemente, a busca por melhor posicionamento.

Conforme apresentado na Figura 1, o presente artigo propõe um modelo de gestão estratégica da informação já validado na indústria moveleira que permite a utilização da gestão do conhecimento, da inteligência estratégica e de contramedidas.

A primeira etapa a ser realizada neste processo, é a elaboração do planejamento estratégico da empresa de maneira formal com o envolvimento dos principais gestores da organização. À medida que a empresa descentraliza sua estrutura, deve ir expandindo esta participação para os demais níveis. A proposta é que haja maior participação possível dos colaboradores que participam do processo de tomada de decisão da empresa. Com isto, se tem a diluição dos riscos inerentes ao processo de negócio.

Por conseguinte, torna-se necessário o diagnóstico interno, bem como o monitoramento prospectivo do ambiente. Aqui se ressalta a importância da informação interna e externa para o processo de gestão estratégica. Observa-se que a informação

Modelo de gestão estratégica da informação

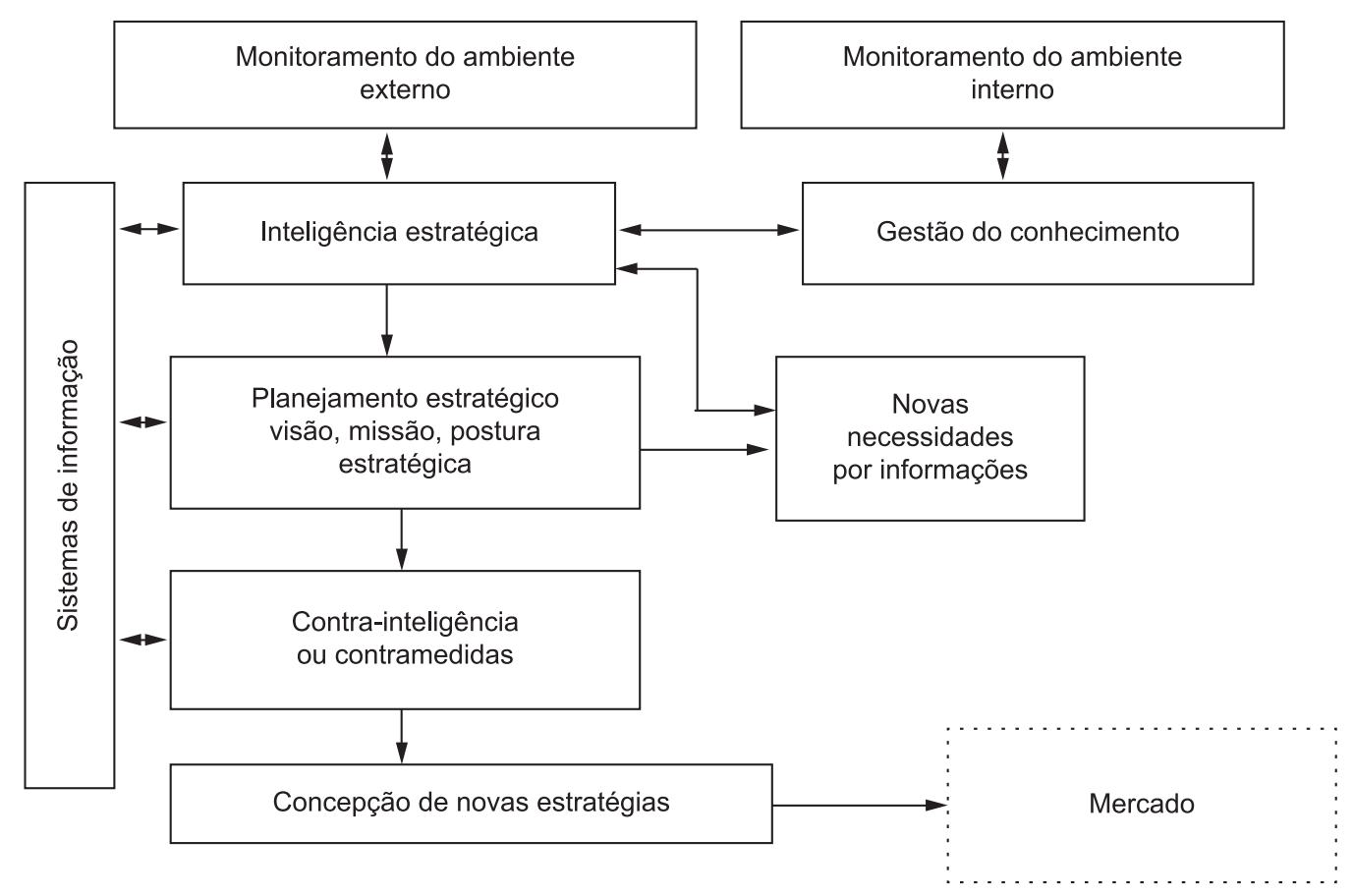

Figura 1. Modelo da gestão estratégica da informação. Fonte: Adaptado de Lesca (1996). 
externa proveniente do monitoramento do ambiente exerce um papel fundamental para a análise de como a empresa está posicionada no atual cenário econômico. Estas informações proporcionam condições para que haja um reposicionamento, bem como a concepção de estratégias possíveis que atendam aos objetivos já estabelecidos. O processo deve ser sistêmico e realimentado com novas informações (ANSOFF; McDONNELL, 1993; LESCA, 1996; BUKOWITZ; WILLIAMS, 2002; MILLER, 2002).

Aqui devem ser definidas as diretrizes, ou seja, as estratégias, políticas e objetivos a serem seguidos. Depois da elaboração do planejamento, este deve ser revisto de forma periódica de acordo com o monitoramento do ambiente. De acordo com os planos de ação e das necessidades por informação, a indústria deve utilizar os sistemas como recurso estratégico.

Para tanto, as empresas devem utilizar os sistemas de processamento de transações que permitam um fluxo de informações entre os setores e unidades de negócio. Associado a isto seria necessária a utilização de outros sistemas, como, por exemplo: sistemas colaborativos, sistemas de informações gerenciais e sistemas de apoio à decisão.

Cabe ressaltar que, à medida que se utilizam sistemas mais avançados, aumenta a quantidade de recursos que podem ser usados nos cruzamentos entre variáveis e na elaboração de cenários, bem como, melhora a difusão e o compartilhamento da informação.

A descentralização é um ponto importante que deve ser observada. Por meio dela, o gestor delega as atividades operacionais, dedicando assim, mais tempo para as questões táticas e estratégicas. Além disto, é necessária a construção de um ambiente mais participativo que estimule a iniciativa, a criatividade e o trabalho colaborativo, permitindo um clima organizacional agradável. Desta forma, os recursos humanos estarão envolvidos e motivados a compartilhar as informações e experiências adquiridas.

Com o ambiente propício instaurado, pode-se utilizar a gestão do conhecimento, transformando assim dados, informações e experiências tácitas (pertencentes ao indivíduo), em conhecimento explícito. Estas informações serão armazenadas numa memória organizacional, nos sitemas de informação da empresa, de onde poderão ser recuperadas. Cabe ressaltar que a vivência, a experimentação proveniente do dia a dia na organização geram um conhecimento implícito, pertencente ao indivíduo, que também faz parte do "como fazer" (Know how) da empresa e, portanto, também deve ser compartilhada. Em outras palavras, a gestão do conhecimento procura armazenar informações informais, provenientes de competências e habilidades geradas pela organização e pelo indivíduo. Este repositório também pode servir de base de dados para a inteligência competitiva na busca de informações antecipativas.

O monitoramento do ambiente externo deve ser feito de forma sistêmica a fim de identificar possíveis oportunidades e ameaças. A inteligência competitiva deve ser utilizada como recurso de prospecção a fim de coletar sinais fracos de mercado. A concretização destes sinais permite à empresa investir seus recursos na qualificação de suas competências e habilidades, fazendo, assim, frente aos novos desafios.

As técnicas de inteligência utilizam vários recursos, sejam estes por meio de visitação a feiras, acompanhamento das públicações científicas sobre áreas de interesse da empresa, registro de patentes, acompanhamento de estatísticas, análise dos concorrentes, entre outras técnicas. Este monitoramento, por exemplo, pode ser feito com o auxílio da tecnologia da informação, por meio da utilização de softwares (robôs de busca, mineradores de dados, agentes inteligentes, entre outros) utilizando-se como base a Internet. Outras informações podem ser coletadas diretamente na memória organizacional, existente na empresa em forma de banco de dados. Com o auxílio da gestão do conhecimento pode-se identificar dados e elementos provenientes da percepção do colaborador, que podem transmitir sinais fracos sobre uma possível movimentação do concorrente.

Com o cruzamento destas informações, provenientes do ambiente interno, pode-se orientar o processo de inteligência. Esta composição de dados e informações forma um mosaico que permite, conforme Lesca (1996), a construção de um quebra-cabeça, que proporcionará visualizar uma possível tendência, que poderá ocorrer em um futuro próximo.

Deve-se salientar que o processo de Inteligência, obrigatoriamente, deve usar fontes de informações que sejam públicas, obedecendo a um procedimento legal e ético.

A inteligência competitiva, além de proporcionar informações antecipativas, fornece condições de estabelecer contramedidas de inteligência. Estas contramedidas permitem que a empresa resguarde sua imagem, seus recursos informacionais e seu patrimônio. A proposta reside em estabelecer estratégias de comunicação com o mercado sem se expor aos seus concorrentes. Por exemplo, a empresa que possui um site na Internet, no qual reúne informações institucionais, tais como o seu histórico, informações sobre a empresa, fotos mostrando as unidades de negócio e sua localização no território nacional e, muitas vezes, fotos do setor produtivo, deve ter uma estratégia e uma política de comunicação pré-definida, a fim de resguardar informações estratégicas para a empresa.

Outro exemplo é quando participa de feiras, em que existe a divulgação das informações sobre a empresa e seus produtos por meio de folders. Seja qual for a 
forma de promoção, é necessário ter em mente que existe certo grau de exposição da empresa ao mercado. Este nível de exposição deve ser controlado, caso contrário, estariam se tornando públicas informações relevantes, que permitam ao concorrente conhecer o processo produtivo, a tecnologia empregada, o nível de qualificação da mão de obra, a estrutura de custos e assim por diante.

O objetivo das contramedidas ou da contrainteligência é resguardar dados, informações e conhecimento estratégicos da organização. O uso de técnicas como a gestão do conhecimento, a inteligência competitiva e de contramedidas em conjunto proporciona à empresa condições maiores de articulação na busca de melhor posicionamento competitivo no mercado.

\section{Conclusão}

De acordo com o exposto, as empresas em um ambiente competitivo devem elaborar suas estratégias fundamentadas em informações antecipativas, fruto da coleta de informações e da recuperação do conhecimento gerado pela empresa, embasadas em técnicas de coleta de informações como a inteligência competitiva e a gestão do conhecimento.

Conforme apresentado neste artigo, as empresas em um ambiente competitivo devem definir estratégias adequadas com o intuito de orientar seus esforços, competências e habilidades, que lhe permitam antecipar-se aos demais. Isto requer um exercício diário de monitoramento do ambiente interno e externo, que proporciona condições de elaborar um planejamento e desenvolvimento de estratégias adequadas.

Conforme a amostra da pesquisa, apenas um pequeno grupo seleto de empresas planejam os movimentos que serão feitos no mercado, procurando resguardar suas informações estratégicas. Estas empresas definem o que a concorrência deve enxergar, formulando assim estratégias de comunicação com o mercado, sem a necessidade de se expor, agindo com cautela e resguardo, sem perder a capacidade de competitividade.

Tudo isto é possível, com a utilização de forma eficiente de técnicas de inteligência competitiva e da gestão do conhecimento que apoiam o processo de planejamento estratégico destas organizações, conforme apresentado no modelo.

No entanto, quando se refere à gestão do conhecimento, pode-se observar que a gestão do conhecimento é pouco utilizada ainda pelas empresas estudadas. Assim sendo, deixa-se de recuperar informações importantes provenientes do fluxo de informações, da sinergia gerada pelo dia a dia da empresa, por falta da existência de uma memória organizacional e da conscientização de sua importância perante os colaboradores. Este repositório proporciona condições de armazenar informações informais que poderiam ser recuperaradas, aumentando assim a capacidade de resposta da empresa.

Sendo assim, deve-se buscar a decentralização das empresas, incentivando a participação e a troca de informações, motivando as pessoas a compartilhar vivências e experiências, previlegiando, desta forma, a difusão e a sistematização da informação. Aliado a isto, a tecnologia e os sistemas de informação devem ser vistos como um recurso estratégico, que proporciona uma tomada de decisão mais rápida, com qualidade, que permite ações antecipativas, que podem ser traduzidas em maior dinâmismo, flexibilidade e capacidade de resposta.

Com o uso da inteligência competitiva e da gestão do conhecimento em seu processo de negócio a empresa pode estar atenta aos movimentos de seus concorrentes, buscando condições antecipativas e traçando estratégias de comunicação com o mercado de forma adequada, sem se expor desnecessariamente.

As empresas não devem esquecer que o mercado nada mais é que um grande jogo de xadrez, altamente competitivo, no qual, muitas vezes, não se permitem margens de erros. Quem se posiciona melhor e ganha o jogo é aquele que consegue perceber as estratégias de seu oponente sem se descuidar de proteger as suas!

\section{Referências}

ALTER, S. Information systems: a management perspective. Canada: The Benjamin/Cummings Publishing Company, 1996.

ANSOFF, H. I.; McDONNELL, E. J. Implantando a administração estratégica. São Paulo: Atlas, 1993.

ASSOCIAÇÃO BRASILEIRA DAS INDÚSTRIAS DO MOBILIÁRIO - ABIMÓVEL. Panorama da indústria brasileira de móveis. São Paulo, 2007.

ASSOCIAÇÃO DAS INDÚSTRIAS DE MÓVEIS DO ESTADO DO RIO GRANDE DO SUL - MOVERGS. A indústria de móveis. Bento Gonçalves: MOVERGS, 2009.

BOWDITCH, J. L.; BUONO, A. F. Elementos de comportamento organizacional. São Paulo: Pioneira, 1999.

BUKOWITZ, W. R.; WILLIAMS, R. L. Manual de Gestão do Conhecimento: ferramentas e técnicas que criam valor para a empresa. São Paulo: Bookman, 2002.

CHIAVENATO, I. Administração nos novos tempos. Rio de Janeiro: Campus, 2009a.

CORNELLA, A. Los recursos de información. Madrid: McGraw-Hill, 1994.

DAVENPORT, T. H. Motivar, retener y crear valor: en la era del conocimiento. Barcelona: Deusto, 2006.

DAVENPORT, T. H.; HARRIS, J. G. Competing on analytics. Massachussets: Harvard Business SCH, 2007.

DAVENPORT, T. H.; PRUSAK, L. Conhecimento empresarial: como as organizações gerenciam o seu capital intelectual. Rio de Janeiro: Campus, 1998.

FESTERVAND, T. A.; MURREY JUNIOR, J. H. Competitive Intelligence Systems for the Independent Insurance Agent. CPCU Journal, v. 46, n. 1, p. 31-37, mar. 1993. 
FULD, L. Inteligência competitiva. Rio de Janeiro: Campus, 2008.

KOTLER, P.; KELLER, K. L. Administração de Marketing. 12. ed. São Paulo: Prentice Hall Brasil, 2006.

LAUDON, K. C.; LAUDON, J. P. Management Information Systems. 7th ed. New Jersey: Prentice Hall, 2002.

LESCA, H. Inteligência competitiva para decisão estratégica. Porto Alegre: PPGA, UFRGS, 1996. Documento de palestra.

LESCA, H.; FREITAS, H.; CUNHA JUNIOR, M. Como produzir um senso útil para as ações dos dirigentes. Revista Eletrônica de Administração, n. 3, 1996.

LUECAL, S.; DAHL, P. Gathering Competitive Intelligence. Management Quarterly, v. 36, n. 3, p. 2-10,1995.

McGEE, J.; PRUSAK, L. Gerenciamento Estratégico da Informação: aumente a competitividade e a eficiência de sua empresa utilizando a informação como uma ferramenta estratégica. Rio de Janeiro: Campus, 1998.

MILLER, J. P. O milênio da Inteligência Competitiva. Porto Alegre: Bookman, 2002.

NONAKA, I.; TAKEUCHI, H. Criação do conhecimento na empresa: como as empresas japonesas geram a dinâmica da Inovação. Rio de Janeiro: Campus, 1997.

NONAKA, I.; TAKEUCHI, H. Gestão do conhecimento. Rio de Janeiro: Artmed, 2008.

PORTER, M. E. Estratégias Competitivas: Técnicas para análise de indústrias e da concorrência. 5. ed. Rio de Janeiro: Campus, 1991.
PORTER, M. E. Vantagem Competitiva: criando e sustentando um desenvolvimento superior. Rio de Janeiro: Campus, 1992.

PRESCOTT, J. E.; MILLER, S. H. Inteligência competitive na prática. Rio de Janeiro: Campus, 2002.

SCHERMERHORN, J. R.; HUNT, J. G.; OSBORN, R. N. Fundamentos de comportamento organizacional. Porto Alegre: Bookman, 1999.

SPHINX BRASIL. Sphinx. versão 2.x. 1999. Disponível em: <sphinxbrasil.com/po/index.php>. Acesso em: 11 jun. 2007.

SPSS BRASIL. versão for Windows 12.0. Disponível em: <www.spss.com.br>. Acesso em: 11 jun. 2007.

STAIR, R. M. Princípios de Sistemas de Informação: uma abordagem gerencial. Rio de Janeiro: Livros Técnicos e Científicos, 1998.

STAIR, R. M.; REYNOLDS, G. W. Princípios de Sistemas de Informação: uma abordagem gerencial. Rio de Janeiro: Livros Técnicos e Científicos, 2002.

TAPSCOTT, D.; CASTON, A. Mudança de paradigma: a nova promessa da tecnologia da informação. São Paulo: Makron-McGraw-Hill, 1995.

TURBAN, E.; McLEAN, E.; WETHERBE, J. Tecnologia da Informação para gestão: Transformando os negócios na economia digital. 3. ed. Porto Alegre: Bookman, 2004.

VARGAS, L. M. Por que as patentes são importantes para as empresas competirem economicamente? Jornal do Comércio, Porto Alegre, p. 3, 20 ago. 1996. 